\title{
AvaliaÇÃo da MUdANÇA NAS RELAÇÓES INTERPESSOAIS ATRAVÉS DO CCRT. ESTUDO DE CASO PSICANALÍTICO ${ }^{1}$
}

\author{
ASSESSMENT OF CHANGE IN \\ INTERPERSONAL RELATIONSHIPS THROUGH THE CCRT. \\ A CASE STUDY OF PSYCHOANALYSIS
}

EVALUACIÓN DE LOS CAMBIOS EN LAS RELACIONES INTERPERSONALES A TRAVÉS DE LA CCRT. ESTUDIO DE CASO DE PSICOANÁLISIS

Ana Isabel Manta Salgado* António Augusto Pazo Pires**

\section{Resumo}

O objetivo foi perceber a evolução das relaçóes interpessoais de uma paciente ao longo da sua psicanálise com a duração de quatro anos. $\mathrm{O}$ método Core Conflictual Relationship Theme foi aplicado para identificar os episódios de desejos, respostas do outro e respostas do self. Foram analisadas as notas de sessóes em sete momentos diferentes: no início, seis, 12, 18, 24, 30 e 36 meses. Através da análise do conflito central presente nos episódios relacionais observa-se uma evolução ao longo da psicanálise que pôde ser confirmada pelos dados clínicos. A paciente passa de desejos de se opor, magoar e controlar os outros, ser distante e evitar conflitos no início da terapia para o desejo de ser amada, compreendida e ajudar os outros no fim da terapia. Quanto às respostas dos outros a paciente vai alternando ao longo da análise entre senti-los como rejeitantes e que gostam dela. Quanto às respostas do self uma alternância entre sentimentos depressivos e autoaceitação.

Palavras-chave: psicanálise; CCRT; relações interpessoais; investigação de processos.

\footnotetext{
* Instituto Superior de Psicologia Aplicada - IU, Lisboa, Portugal.

** Instituto Superior de Psicologia Aplicada - IU, Lisboa, Portugal.
} 


\section{Abstract}

The aim was to understand the evolution of the interpersonal relationships of a patient through her four years of psychoanalysis. The Core Conflictual Relationship Theme method was applied to identify episodes in the reported Wishes, the Responses from Others and Responses of the Self. The notes of the sessions were analysed in the beginning, six, 12, 18, 24, 30 and 36 months. The conflict in the relational episodes shows an increase in self-confidence, and positive responses about self, and decrease of negative responses of others. We see a change in the patient from the desire to hurt and control others, being distant and avoiding conflicts at the beginning of the psychoanalysis to the desired to be loved, understood and helping others at the end. On responses of the others she alternates between feeling rejected and they like her. On responses of the self we see an alternation between depressive feelings and self-acceptance.

Keywords: psychoanalysis; CCRT; interpersonal relationships; process research.

\section{RESUMEN}

El objetivo era comprender la evolución de las relaciones interpersonales de un paciente a través de sus cuatro años de psicoanálisis. El método Core Conflictual Relationship Theme se aplicó para identificar los episodios de los deseos reportados, respuestas de los demás y las respuestas de sí mismo. Las notas de las sesiones se analizaron en 7 ocasiones diferentes: principio, seis, 12, 18, 24, $30 \mathrm{y}$ 36 meses. A través del análisis del conflicto central en este episodios relacionales se observa una evolución a lo largo del psicoanálisis que podría ser confirmada por los datos clínicos. El conflicto en los episodios relacionales muestra un aumento de confianza en sí mismo, y las respuestas positivas sobre lo self, y la disminución de las respuestas negativas de los demás. Vemos un cambio en el paciente desde el deseo de herir y controlar a los demás, ser distante y evitar conflictos en el comienzo del psicoanálisis a la que desea ser amado, comprendido y ayudar a otros al final de la terapia. En las respuestas de los demás se alterna entre sentirse rechazada y les gusta ella. En las respuestas del self vemos una alternancia entre sentimientos depresivos y la auto-aceptación.

Palabras clave: psicoanálisis; CCRT; relaciones interpersonales; investigación de los procesos.

As dificuldades no relacionamento com os outros e o sofrimento associado são razões importantes pelas quais as pessoas procuram uma psicanálise. Até 
mesmo quando as pessoas iniciam uma psicanálise com o propósito expresso de aliviar os sintomas, revelam e trabalham frequentemente problemas nas relaçóes interpessoais. Na teoria psicanalítica, o carácter da pessoa é enfatizado como um fator determinante na formação dos sintomas e padrôes relacionais (Kets de Vries \& Persow, 1991, citado por Wilczek, Weinryb, Barber, Gustavsson, \& Asberg, 2004). A Psicanálise surge como uma forma de lidar com esse sofrimento psicológico que pode ser manifestado de diversas formas, como sintomas, dificuldades de adaptação, dificuldades relacionais, entre outras (Baudry, 1995). De acordo com Klockars (2004), a psicanálise distingue-se de outros métodos terapêuticos, fundamentalmente, pelo uso da associação livre, pelo significado e poder que confere à investigação de fenómenos inconscientes e pela importância que atribui à interpretação. Estas especificidades visam o insight do paciente, a resolução dos seus conflitos intrapsíquicos e consequentemente a mudança psicoterapêutica.

As intervençóes interpretativas usadas em psicanálise servem para aumentar o insight do paciente sobre os conflitos repetitivos que sustentam os seus problemas (Gabbard, 2004). As intervenções de suporte servem para fortalecer capacidades que estão temporariamente inacessíveis ao paciente.

A transferência, definida como a repetição de experiências passadas nas relaçôes interpessoais presentes, constitui outra dimensão importante da relação terapêutica. Segundo Leichsenring e Leibing (2007), na psicanálise a transferência é considerada como a primeira fonte de entendimento e mudança terapêutica. Usando medidas seguras de transferência, vários estudos empíricos mostraram que as mudanças nos padrões transferenciais (fator mediador) estão significativamente relacionadas com o resultado da psicoterapia psicanalítica (Crits-Christoph \& Luborsky, 1998). A transferência e contratransferência são um par indissociável. As perspectivas mais recentes enfatizam a elaboração da contratransferência como forma de evitar a atuação dentro da situação de análise. A elaboração da contratransferência é o modo pelo qual o analista poderia conduzir o seu afeto no sentido de uma simbolização, isto é, num caminho em direção à palavra, dando- lhe sentido através do desenvolvimento de redes fantasmáticas, impedindo que venha a emergir no campo do ato (Andrade \& Herzog, 2011).

Nos últimos 15 anos, foram apresentadas várias medidas dos padrôes de relacionamento centrais ou formulaçóes dinâmicas na literatura de investigação clínica. O método Core Conflictual Relationship Theme (CCRT) de Crits-Christoph e Luborsky (1998) é uma das medidas que receberam muita atenção por parte dos investigadores. Com respeito à validade, vários resultados apoiaram a hipótese de que o método CCRT parece avaliar um construto consistente com muitas características do padrão de transferência descrito por Freud (Fried, Lu- 
borsky \& Crits-Christoph, 1992, citado em Barber, Luborsky, Crits-Christoph \& Diguer, 1995).

Segundo Luborsky (1998a), a formação do CCRT é uma história de sucesso, uma vez que transformou um útil conceito clínico numa medida quantitativa clínica ainda mais útil. $\mathrm{O}$ autor afirma que o CCRT faz aquilo que os clínicos fazem tipicamente no decurso de cada sessão: desenvolver uma formulação dos padrôes de relacionamento central dos pacientes de forma a poder derivar interpretaçóes que se ajustem à formulação. Com o uso deste método, existe o suporte de um sistema confiável para ajudar nesta tarefa rotineira necessária.

O CCRT como uma medida de personalidade ou estilo de relacionamento é uma formulação guiada sistematicamente que é capaz de produzir julgamentos clínicos seguros. Foi desenvolvido como sendo um sistema de análise de conteúdo do padrão de relação central em sessôes de psicoterapia. O CCRT foi descoberto durante investigaçóes sobre aliança terapêutica e cresceu de um esforço dos clínicos para derivar interpretaçóes das narrativas dos pacientes (Luborsky, 1998b).

O objetivo deste estudo é perceber a mudança no padrão relacional numa Psicanálise. Para tal utilizou-se o método de análise Core Conflictual Relationship Theme.

\section{Método}

\section{A paciente}

A Maria tinha no início da análise 43 anos, era divorciada, sem filhos, e vivia sozinha. Com formação de nível superior e um trabalho estável, com realização profissional mais ou menos satisfatória. Ela é a mais velha de quatro irmãos, dois rapazes e duas raparigas. Quando tinha cerca de dois anos e meio a mãe morreu, e ficou a viver com o pai na casa dos avós paternos, onde existia o culto da mãe pelos avós e pelo pai. Aos seis anos foi pela primeira vez a um psicólogo em consequência de uma enurese secundária. $\mathrm{O}$ pai casou-se novamente quando ela tinha 10 anos, nas suas palavras algo que ela nunca esperou que o pai the fizesse, e o pai mudou de casa. No ano seguinte nasceu um irmão e a Maria foi para um colégio interno, que também tinha sido frequentado pela sua mãe, razão que apresenta para não ter sentido falta da casa dos avós paternos a quem dizia estar muito ligada. $\mathrm{Na}$ adolescência começou a apresentar um quadro fóbico, com sintomas de claustrofobia, que se manteve na idade adulta. 
Cerca de 3 anos antes do início da análise o pai morreu e ela foi abandonada pelo marido, que se apaixonou por outra mulher. Maria vive uma dupla perda e como "fuga" foi trabalhar para o estrangeiro. Os sintomas fóbicos e sentimentos depressivos acentuaram-se e, por essa razão, procurou ajuda. Durante um ano e meio fez psicoterapia psicanalítica três vezes por semana.

Voltou a Portugal por razóes profissionais e, querendo continuar o seu tratamento, iniciou a sua psicanálise com a frequência de três vezes por semana. Revela comportamentos de excessivo controlo relacional como forma de evitar relaçóes de grande proximidade com medo de ser abandonada, por um lado, ou de dependência total, por outro. Profissionalmente, evita cargos de chefia e situações de confronto, especialmente com as hierarquias, o que de certa maneira the provoca muito desconforto porque as interpreta como desvalorizaçóes.

\section{O psicanalista e a psicanálise}

O psicanalista (segundo autor deste estudo) tem 20 anos de experiência como psicólogo clínico e formação em Psicanálise pela Sociedade Portuguesa de Psicanálise, é membro da IPA.

A psicanálise teve a duração de 3 anos e 8 meses num total de 384 sessóes. As sessões tiveram a duração de 50 minutos, numa frequência de três vezes por semana com a paciente em divã.

\section{Instrumento}

Foi utilizado o método de análise The Core Conflictual Relationship Theme (CCRT), elaborado por Lester Luborsky e Paul Crits-Christoph em 1998. Para melhor compreensão do instrumento foi feita uma tradução para português pelo primeiro autor deste estudo.

Este método de análise é tipicamente aplicado em narrativas sobre relaçôes interpessoais que são contadas espontaneamente por pacientes durante as sessóes de psicoterapia. Nessas narrativas é identificada a presença mais frequente de três elementos: (a) desejos (W), necessidades, ou intençóes do sujeito; (b) respostas dos outros (RO) para com o sujeito; e (c) respostas do sujeito (RS) para com os outros. Este método avalia os três elementos através de um sistema de categorias feito à medida que é descrito como um padrão de ouro porque utiliza as próprias palavras do paciente e retém assim a sua proximidade ao contexto clínico (Luborsky, 1998b). Contudo, para propósitos de investigação, quando os dados do paciente são agrupados é necessário traduzir as formulações CCRT feitas à 
medida em categorias standard (padrão). O objectivo do método CCRT é, então, encontrar as categorias standard mais frequentes (ou categorias standard agrupadas) para W (desejos), RO (resposta do outro) positiva e negativa e RS (resposta do self) positiva e negativa. Essas categorias mais frequentes constituem o conflito principal (Moreno et al., 2005).

No decurso do seu desenvolvimento, o método CCRT tem provado ser útil em estudos transversais e estudos de caso. Um estudo de caso com material narrativo recolhido de várias sessóes permite a procura de padróes de relação específicos para objetos individuais, vida ou fases de terapia, e settings da sessão. Protocolos de sessões literais servem como uma base de texto nos estudos.

Segundo Bond, Hansell e Shevrin (1987), o método CCRT possui uma mistura de dois componentes particularmente atrativa: 1) permanece próximo da ocorrência natural de mudança em psicoterapia; e 2) fornece aos avaliadores um conjunto relativamente explícito de diretrizes para fazer as avaliaçóes essenciais. Adicionalmente, os julgamentos requerem uma das habilidades que os psicoterapeutas usam intuitivamente na prática de psicoterapia, a atenção a temas repetitivos nos relatos de um paciente sobre o seu relacionamento com os outros.

\section{Procedimento}

Os dados usados nesta pesquisa foram notas de sessóes de uma psicanálise de uma paciente seguida pelo segundo autor do estudo. As notas têm um carácter descritivo e não foram feitas com objetivo de investigação, mas sim de supervisão. Foram escritas em discurso direto, procurando relatar o mais fielmente possível as falas do psicanalista e da paciente. $\mathrm{O}$ estudo foi realizado após o fim da psicanálise. Foram seguidos todos os procedimentos éticos previstos para a elaboração de um estudo de caso tendo sido pedido o consentimento informado da paciente. Os dados foram analisados pelo segundo autor deste estudo no contexto da sua dissertação de mestrado.

Na primeira fase, o segundo autor do estudo leu todas as sessóes de forma a conhecer a paciente, bem como a sua problemática. Seguiu-se uma fase de treino do CCRT, na qual selecionaram-se algumas sessóes aleatoriamente, foram identificados os episódios relacionais e procedeu-se à cotação de forma independente pelos dois autores do estudo. As discrepâncias entre os dois avaliadores foram discutidas, e encontrada uma concordância para a maioria dos episódios.

Posteriormente identificaram-se sete momentos da terapia a serem avaliados: início, seis meses, 12, 18, 24, 30 e 36 meses. Procedeu-se à leitura das sessóes 
em cada um desses períodos a fim de se identificarem os episódios relacionais. Procurou encontrar-se uma série de 10 episódios relacionais por semestre, uma vez que esse número é suficiente para que o conteúdo do CCRT tenha uma consistência considerável (Luborsky, 1998b). Foram necessárias entre 6 e 15 sessóes seguidas para se encontrar os 10 episódios.

Uma vez identificados os episódios, foi reconhecida outra pessoa com quem a paciente estava a interagir (terapeuta, o self, ou outra). A etapa seguinte foi a cotação desse mesmo episódio relacional como desejos, necessidades ou intençóes; resposta do outro; ou resposta do self. Esses componentes foram primeiramente cotados em categorias feitas à medida e, posteriormente, foram correspondidos com uma lista de categorias standard do CCRT, edição 2. Pelo facto de dentro das listas de categorias standard existirem algumas sobreposiçóes, por exemplo, pode haver algumas sobreposiçóes no significado e função das categorias standard dos desejos "ser independente" e "ser eu próprio", tinha sido descoberto que as categorias standard podiam ser condensadas ou agrupadas em grupos menores (Barber, Crits-Christoph, \& Luborsky, 1998). Isto é, os 33 desejos das categorias standard poderiam ser condensados em apenas 8 categorias designadas agrupamentos das categorias standard CCRT. Os $33 \mathrm{ROs}$ podiam ser condensados em 8 agrupamentos das categorias standard para as RO, e os $31 \mathrm{RSs}$ podiam ser condensados em 8 agrupamentos de RS. Então, fizemos corresponder todos os componentes cotados da Edição 2 das categorias standard à Edição 3 dos agrupamentos das categorias standard. Um sexto dos episódios foi mais uma vez cotado de forma independente pelos dois avaliadores sendo encontrada novamente uma concordância na maioria dos episódios.

Em cada momento avaliado resultou uma lista de desejos, resposta do outro e resposta do self mais frequente, que identificou os conflitos principais da paciente. Estes descrevem os padrôes de relação mais repetitivos e mostram muitas semelhanças ao conceito de transferência (Luborsky, 1998c).

A última etapa consistiu na comparação dos diferentes momentos avaliados e perceber as mudanças da paciente no nível dos três componentes, ou seja, as mudanças nos conflitos principais.

\section{Resultados}

Seguidamente apresentamos o CCRT final, resultante da Edição 3 das categorias standard aglomeradas, para cada momento da terapia avaliado. A Tabela 1 apresenta um quadro com os desejos, respostas positivas e negativas do outro e respostas positivas e negativas do self ao longo da terapia. 
Tabela 1 CCRT final da paciente ao longo da terapia

\begin{tabular}{|c|c|c|c|}
\hline \multicolumn{4}{|c|}{ CCRT final } \\
\hline Momentos da terapia & $\begin{array}{l}\text { Desejos, necessida- } \\
\text { des ou intençốes }\end{array}$ & $\begin{array}{l}\text { Respostas do outro } \\
\text { (Negativa / Positiva) }\end{array}$ & $\begin{array}{l}\text { Respostas do Self } \\
\text { (Negativa / Positiva) }\end{array}$ \\
\hline \multirow{2}{*}{ Sessões iniciais } & \multirow{2}{*}{$\begin{array}{c}\text { Opôr, magoar e } \\
\text { controlar os outros }\end{array}$} & Rejeitante e opositor & $\begin{array}{c}\text { Desapontada e } \\
\text { depressiva }\end{array}$ \\
\hline & & Compreensivo & Respeitada e aceite \\
\hline \multirow{2}{*}{6 meses } & \multirow{2}{*}{$\begin{array}{l}\text { Ser distante e } \\
\text { evitar conflitos }\end{array}$} & $\begin{array}{l}\text { Descontente; Re- } \\
\text { jeitante e opositor }\end{array}$ & $\begin{array}{c}\text { Desapontada e } \\
\text { depressiva }\end{array}$ \\
\hline & & Útil; compreensivo & Respeitada e aceite \\
\hline \multirow{2}{*}{12 meses } & \multirow{2}{*}{$\begin{array}{l}\text { Ser distante e evitar } \\
\text { confltos; ser próxima } \\
\text { e aceite; ser amada } \\
\text { e compreendida }\end{array}$} & Rejeitante e opositor & $\begin{array}{c}\text { Desapontada e } \\
\text { depressiva }\end{array}$ \\
\hline & & $\begin{array}{l}\text { Gosta de mim; } \\
\text { compreende-me }\end{array}$ & Respeitada e aceite \\
\hline \multirow{2}{*}{18 meses } & \multirow{2}{*}{$\begin{array}{l}\text { Afirmar-me e ser inde- } \\
\text { pendente; ser próxima } \\
\text { e aceite; ser amada } \\
\text { e compreendida }\end{array}$} & Controlador & $\begin{array}{l}\text { Desapontada e } \\
\text { depressiva }\end{array}$ \\
\hline & & Gosta de mim & Útil \\
\hline \multirow{2}{*}{24 meses } & \multirow{2}{*}{$\begin{array}{l}\text { Opôr-se, magoar e } \\
\text { controlar os outros; } \\
\text { ser próxima e aceite }\end{array}$} & Rejeitante e opositor & $\begin{array}{l}\text { Desamparada; Desa- } \\
\text { pontada e depressiva }\end{array}$ \\
\hline & & & Respeitada e aceite \\
\hline \multirow{2}{*}{30 meses } & \multirow{2}{*}{$\begin{array}{l}\text { Opôr-se, magoar e } \\
\text { controlar os outros }\end{array}$} & Rejeitante e opositor & $\begin{array}{l}\text { Desapontada e } \\
\text { depressiva }\end{array}$ \\
\hline & & Gosta de mim & Respeitada e aceite \\
\hline \multirow[b]{2}{*}{36 meses } & \multirow{2}{*}{$\begin{array}{l}\text { Ser amada e com- } \\
\text { preendida; alcançar } \\
\text { e ajudar os outros }\end{array}$} & Rejeitante e opositor & $\begin{array}{l}\text { Opôr-se e ma- } \\
\text { goar os outros }\end{array}$ \\
\hline & & Gosta de mim & $\begin{array}{l}\text { Autocontrolada e } \\
\text { autoconfiante }\end{array}$ \\
\hline
\end{tabular}


Pode verificar-se que os componentes $\mathrm{W}, \mathrm{RO}$ e RS não variam muito ao longo da terapia. No nível dos seus conflitos centrais, a paciente mantém-se mais ou menos constante ao longo da terapia.

A Figura 1 mostra a variação dos desejos da paciente ao longo da terapia. No início da terapia, a paciente manifesta uma expressiva vontade de se opor aos outros, confrontá-los e controlá-los, mas no momento seguinte da terapia o desejo mais expressivo passa a ser afastar-se dos outros para evitar conflitos.

Figura 1 - Variação dos desejos CCRT ao longo da terapia

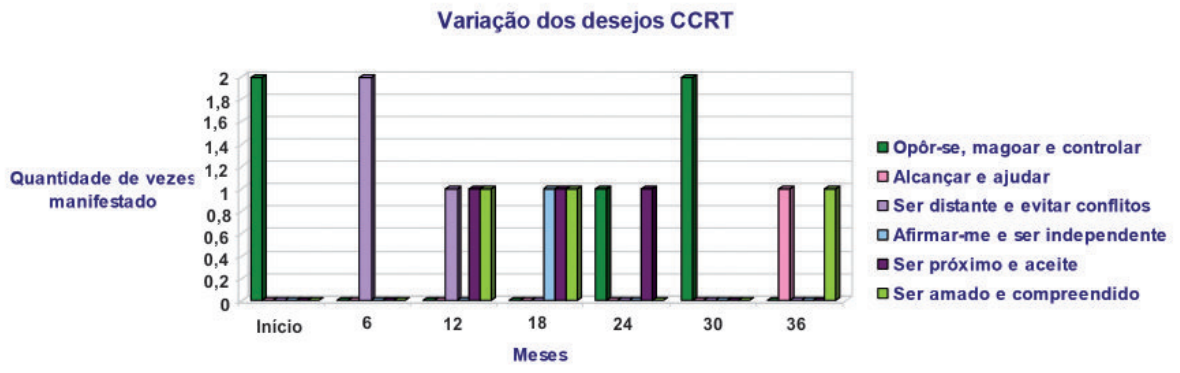

Nos três momentos seguintes (12, 18 e 24 meses), surgem novos desejos como ser próxima e aceite bem como ser amada e compreendida que demonstram uma mudança na sua atitude para com os outros, ela deixa de ser opor-se ou afastar-se para estar próxima e ser aceite, amada e compreendida. Aos 30 meses, o desejo mais expressivo da paciente volta a ser o manifestado no início da terapia, de se opor, confrontar e controlar os outros. A maior mudança acontece no final da terapia (36 meses), uma vez que os desejos mais expressivos sáo alcançar e ajudar os outros e ser amada e compreendida. Do início para o fim da terapia ocorre uma grande mudança, pois os desejos de confrontar e magoar os outros são substituídos pelos desejos de ajudar os outros e ser amada e compreendida por eles.

As respostas do outro serão apresentadas separadamente em respostas positivas e respostas negativas para que seja mais fácil observar as alteraçóes ocorridas. A figura 2 mostra a variação das respostas positivas do outro ao longo da terapia. No início da terapia, a paciente vê o outro como compreensivo, aos 6 meses continua a ver o outro como compreensivo e útil, a partir do $12^{\circ}$ mês surge a resposta do outro gosta de mim que se vai manter como categoria mais expressiva até ao final da terapia, exceto no mês 24 onde não há qualquer referência a respostas positivas do outro. A categoria gosta de mim, aquela que se manifesta em mais meses, aumenta dos momentos intermédios para os momentos finais da terapia. 
Figura 2 - Variação das respostas positivas CCRT do outro ao longo da terapia

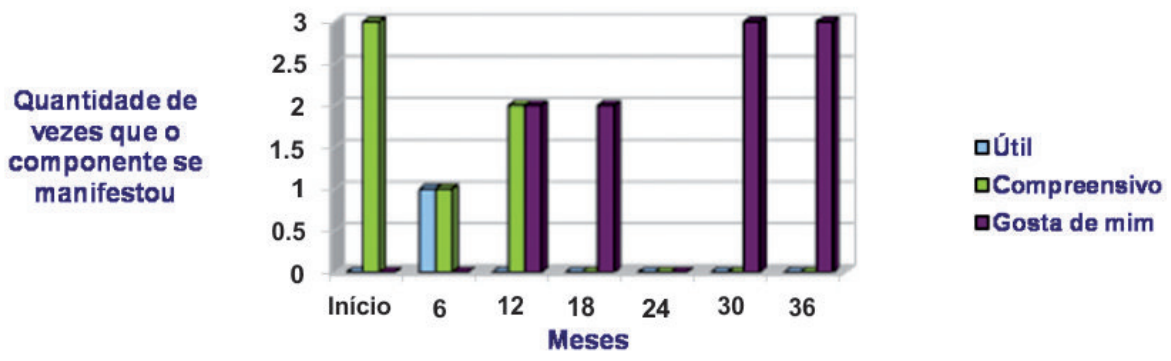

A figura 3 apresenta a variação das respostas negativas do outro ao longo da terapia. Verifica-se uma grande expressão da resposta rejeitante e opositor no início da terapia e uma baixa expressão no final da terapia.

Figura 3 - Variação das respostas negativas CCRT do outro ao longo da terapia Variação das respostas negativas do outro

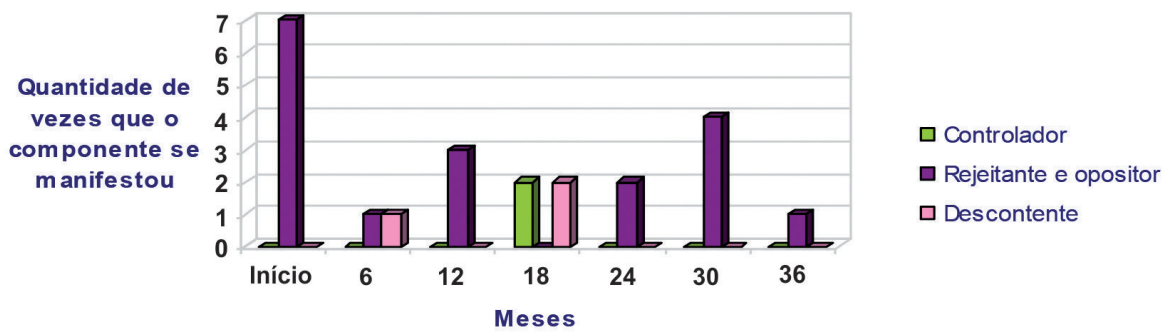

Nos meses 6 e 18 aparecem as respostas controlador e rejeitante e opositor que náo se manifestam no final da terapia. Resumindo, no nível das respostas negativas dos outros dá-se uma mudança positiva uma vez que a resposta rejeitante e opositor que se mantém até ao final da terapia diminui claramente a sua expressão, e as outras respostas que surgem no decorrer da terapia deixam de se manifestar a partir dos 24 meses.

A figura 4 mostra a variação das respostas positivas do self ao longo da terapia. A resposta respeitada e aceite é aquela que ocorre mais vezes ao longo da terapia, com uma frequência semelhante em vários momentos da terapia. A resposta autoconfiante e autocontrolada aparece pela primeira vez nos dados analisados aos 
18 meses, de uma forma discreta e com a mesma expressividade que as respostas respeitada e aceite e útil e no final da terapia volta a manifestar-se como a resposta do self com maior mudança.

Figura 4 - Variação das respostas positivas CCRT do self ao longo da terpia

Variação das respostas positivas do self

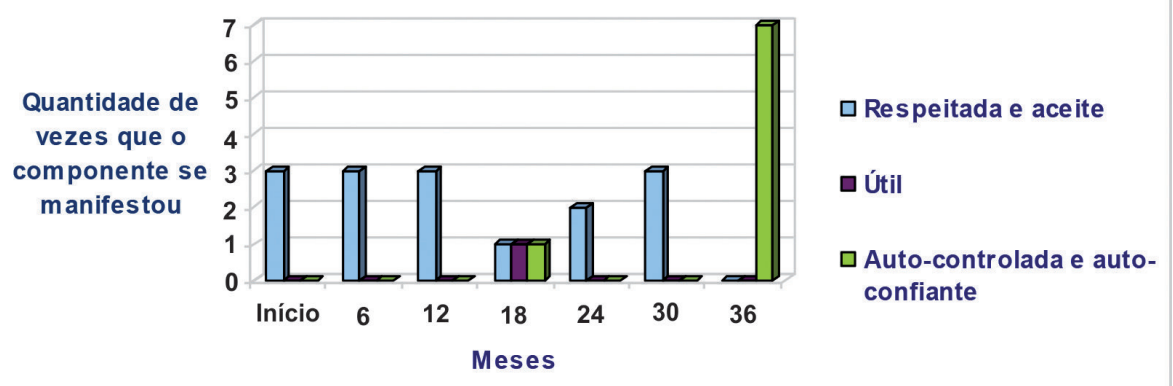

A figura 5 apresenta a variação das respostas negativas do self no decorrer da terapia. A resposta desapontada e depressiva predomina ao longo da terapia com uma expressão bastante elevada. A mudança ocorre no final da terapia onde esta resposta já não se manifesta. A paciente já não se sente desapontada e depressiva. No entanto, dá-se uma alteração negativa na resposta opôr e magoar os outros, que não ocorre durante praticamente todos os momentos da terapia, mas surge no final da terapia, embora com pouca expressão.

Figura 5 - Variaçôes das respostas negativas CCRT do self ao longo da terapia Variação das respostas negativas do self

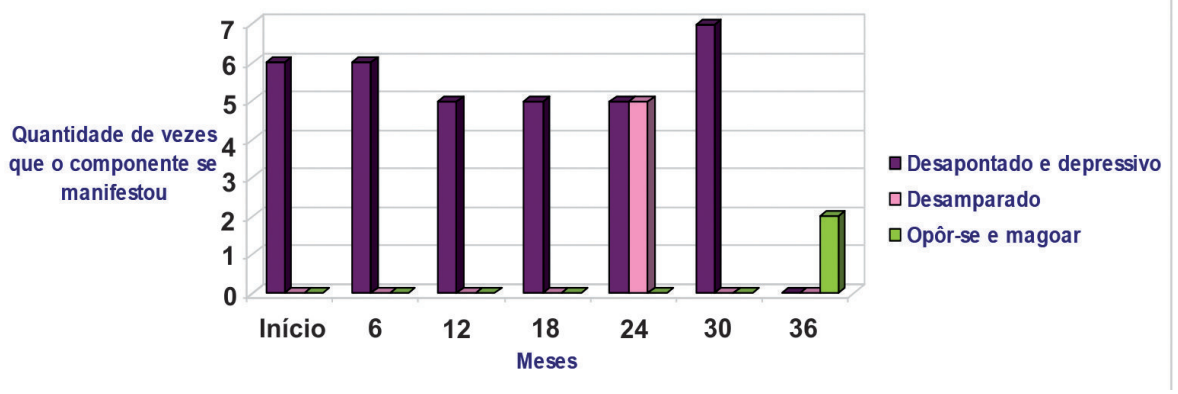


Para finalizar, a figura 6 apresenta a mudança nos desejos, respostas positivas e negativas do outro, e respostas positivas e negativas do self, nos momentos inicial e final da terapia.

Figura 6 - Variação dos W, RO e RS CCRT nos momentos inicial e final da terapia Variação dos W, RO, e RS entre o início e o final da terapia

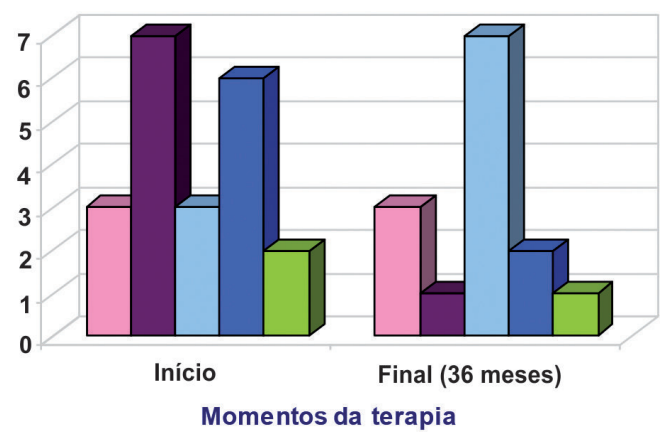

$\square$ Respostas positivas do outro $\square$ Respostas negativas do outro $\square$ Respostas positivas do self $\square$ Respostas negativas do self $\square$ Desejos

No nível dos desejos da paciente, dá-se uma diminuição da frequência do início para o fim da terapia. No entanto, não deixa de ser uma mudança positiva, uma vez que o desejo inicial, como referido anteriormente, era opor-se, magoar e controlar os outros, e o final foi alcançar e ajudar e ser amada e compreendida. A frequência dos desejos baixa do primeiro para o último momento, no entanto os desejos são mais positivos no final da terapia.

Em relação às respostas positivas dos outros não existe qualquer alteração no nível da frequência. As respostas negativas dos outros são aquelas que sofrem a maior mudança, uma vez que no início têm uma frequência bastante elevada e no final têm uma frequência muito baixa. Neste caso, pode afirmar-se que houve uma mudança positiva nas respostas negativas do outro ao longo da terapia.

Relativamente às respostas positivas do self, existe claramente uma mudança positiva uma vez que no início da terapia a frequência destas respostas era mediana e no final da terapia é elevada. As respostas negativas do self também sofrem uma mudança positiva uma vez que sofrem o processo contrário das respostas positivas, ou seja, têm uma frequência elevada no início da terapia e uma frequência bastante mais baixa no final da terapia. 


\section{Discussáo}

A psicanálise pode habilitar os pacientes a alterarem de um modo mais maduro as suas necessidades e desejos, reduzindo assim a sua experiência negativa nas interaçóes com os outros. Neste sentido, no presente estudo, o náo aparecimento do desejo de opor-se, magoar e controlar os outros na fase final da terapia pode ser interessante, talvez refletindo um aumento da capacidade para conter o ódio e os impulsos destrutivos, diminuindo assim a necessidade para usar a projecção como um caminho para exteriorizar esses impulsos (Wilczek et al., 2004). Consequentemente, dá-se uma diminuição das respostas negativas dos outros e do self e um aumento das respostas positivas do self, resultando numa experiência de si mesmo como mais respeitada, aceite, amada e autoconfiante. Encontramos um aumento significativo de respostas positivas do self depois de tratamento. $\mathrm{O}$ mesmo não se verificou para as respostas positivas do outro que se mantiveram iguais em frequência comparativamente ao início e ao final da terapia. No entanto a resposta dos outros mais frequente observada no final do tratamento, gosta de mim, surgiu aos 12 meses de tratamento com uma frequência mais baixa do que aquela que surgiu no final do tratamento. Crits-Christoph e Luborsky (1998) encontraram um aumento significativo nas respostas positivas do outro e do self, um decréscimo nas respostas negativas e ausência de alteração nos desejos quando comparados os resultados do CCRT inicialmente e posteriormente na psicoterapia. Os resultados são concordantes com a experiência clínica de muitos psicanalistas, isto é, os pacientes permanecem fiéis aos seus desejos e vontades, mas melhoram a sua capacidade para narrar para si próprios e para os outros.

Embora o CCRT final consista apenas nas respostas mais frequentes, levando em conta todas as respostas obtidas, verificou-se que a paciente teve um número maior de respostas negativas do que positivas ao longo da terapia, sobretudo em relação às respostas do self. Estes resultados são semelhantes aos obtidos por Luborsky, Barber, Schaffler e Cacciola (1998) em um estudo com 33 participantes em psicoterapia. Luborsky et al. (1998) consideraram a possibilidade de que os seus participantes expressaram respostas mais negativas nas narrativas porque estavam em psicoterapia e por isso experienciavam presumivelmente algumas dificuldades, ou porque se lembravam mais fortemente de experiências negativas, ou porque descrever episódios de relaçâo negativos poderia ajudar a dominá-los (Popp et al., 1996).

Consideramos que os valores de mudança verificados nos componentes ao longo da terapia poderão também ser justificados pelo facto de a paciente já ter 
feito anteriormente uma terapia. Parece-nos então apropriado afirmar que a paciente, após uma fase de encontro e estabilização da relação e contrato terapêutico (Goldman \& Milman, 1978, citado em Howard, Lueger, Mailing \& Martinovich, 1993), retomou o processo de mudança que se iniciara na terapia anterior. Essas conceçóes parecem ser consolidadas pela afirmação do terapeuta, constante nas notas da primeira sessão: "não foi uma primeira entrevista típica [...] parecia que estava a continuar a [anterior] análise”.

Num futuro estudo de caso que utilize o método CCRT a partir de transcriçôes de sessóes, talvez seja interessante utilizar também os sonhos e fantasias e compará-los com o CCRT das sessóes despertas uma vez que Popp et al. (1996) mostraram que há semelhanças significativas entre os temas de relação em sonhos e narrativas despertas. Por outro lado, seria importante compreender que fenómenos e que fatores estiveram na origem das mudanças observadas, nomeadamente responder a questóes relativas à relação terapêutica e às técnicas utilizadas. Apesar de um estudo de caso poder permitir perceber de uma maneira fina processos que seriam impercetíveis através de outro tipo de método, os resultados obtidos neste estudo não nos permitem fazer generalizações.

\section{Referências}

Andrade, A. B., \& Herzog, R. (2011). Os afetos do analista na obra freudiana. Psicologia Clínica, 23(1), 119-131.

Barber, J. P., Luborsky, L., Crits-Christoph, P., \& Diguer, L. (1995). A comparison of Core Conflictual Relationship Themes before psychotherapy and during early sessions. Journal of Consulting and Clinical Psychology, 63(1) 145-148.

Barber, J. P., Crits-Christoph, P., \& Luborsky, L. (1998). A guide to the standard categories and their classification. In L. Luborsky \& P. Crits-Christoph (Eds.), Understanding transference: The core conflictual relationship theme method (pp. 43-54). Washington, DC: American Psychological Association.

Baudry, F. D. (1995). Character. In B. E. Moore \& B. D. Fine (Eds.), Psychoanalysis: The Major Concepts (pp. 196-208). New Haven: Yale University.

Bond, J. A., Hansell, J., \& Shevrin, H. (1987). Locating transference paradigms in psychotherapy transcripts: Reliability of relationship episode location in the Core Conflictual Relationship (CCRT) Method. Psychotherapy, 24(4), 736-749.

Crits-Christoph, P., \& Luborsky, L. (1998). Changes in CCRT pervasiveness during psychotherapy. In L. Luborsky \& P. Crits-Christoph (Eds.), Understanding transference: The core 
conflictual relationship theme method (pp. 151-163). Washington, DC: American Psychological Association.

Gabbard, G. (2004). Long-term psychodynamic psychotherapy: A basic text. Washington: American Psychiatric Publishing.

Howard, K. I., Lueger, R. J., Mailing, M. S., \& Martinovich, Z. (1993). A phase model of psychotherapy outcome: Causal mediation of change. Journal of Consulting and Clinical Psychology, 61(4), 678-685.

Klockars, L. (2004). Linking mind, body and language: Free association revisited. Scandinavian Psychoanalytic Review, 27(2), 105-112.

Leichsenring, F. \& Leibing, E. (2007). Psychodynamic psychotherapy: A systematic review of techniques, indications and empirical evidence. Psychology and Psychotherapy: Theory, Research and Practice, 80, 217-228.

Luborsky, L. (1998a). The early life of the idea for the core conflictual relationship theme. In L. Luborsky \& P. Crits-Christoph (Eds.), Understanding transference: The core conflictual relationship theme method (pp. 3-13). Washington, DC: American Psychological Association.

Luborsky, L. (1998b). A guide to the CCRT method. In L. Luborsky \& P. Crits-Christoph (Eds.), Understanding transference: The core conflictual relationship theme method (pp. 1542). Washington, DC: American Psychological Association.

Luborsky, L. (1998c). Alternative measures of the central relationship pattern. In L. Luborsky \& P. Crits-Christoph (Eds.), Understanding transference: The core conflictual relationship theme method (pp. 289-303). Washington, DC: American Psychological Association.

Luborsky, L., Barber, J., Chaffler, P., \& Cacciola, J. (1998). The narratives told during psychotherapy and the types of CCRTs within them. In L. Luborsky \& P. Crits-Christoph (Eds.), Understanding transference: The core conflictual relationship theme method (pp. 135-150). Washington, DC: American Psychological Association.

Moreno, C. M. L., Schalayeff, C., Acosta, S. R., Vernengo, P., Roussos, A. J., \& Lerner, B. D. (2005). Evaluation of psychic change through the application of empirical and clinical techniques for a 2-year treatment: a single case study. Psychotherapy Research, 15(3), 199-209.

Popp, C. A., Diguer, L., Luborsky, L., Faude, J., Johnson, S., Morris, M., ... Schmidt, K. (1996). Repetitive relationship themes in waking narratives and dreams. Journal of Consulting and Clinical Psychology, 64(5), 1073-1078.

Wilczek, A., Weinryb, R. M., Barber, J. P., Gustavsson, J. P., \& Åsberg, M. (2004). Change in the Core Conflictual Relationship Theme after long-term dynamic psychotherapy. Psychotherapy Research, 14(1), 107-125. 


\section{Nota}

${ }^{1}$ Este artigo foi feito a partir da Dissertação de Mestrado do primeiro autor realizada sob a orientação do segundo autor, para obtenção de grau de Mestre na especialidade de Psicologia Clínica, apresentada no Instituto Superior de Psicologia Aplicada, Lisboa.

Recebido em 01 de julho de 2013 Aceito para publicação em 21 de janeiro de 2014 